\title{
Possible Methods Recovery of Metals from Flotation Tailings Copper-Molybdenum Ores
}

\author{
Natalia K. Algebraistova, Anna S. Markova*, \\ Ivan V. Prokopiev and Denis M. Kolotushkin \\ Siberian Federal University \\ 79 Svobodny, Krasnoyarsk, 660041, Russia
}

Received 17.03.2016, received in revised form 12.04.2016, accepted 30.06.2016

In order to reduce losses of metal with tails cycle of collective flotation of copper-molybdenum ore deposits was performed a preliminary assessment of the effectiveness of enrichment tailings using gravity and flotation methods. The results showed the prospect of using both methods, but in the case of gravity separation is possible to extract valuable component without the addition of flotation reagents, which is beneficial to the process of selection of the bulk concentrate, as well as on the environment.

Keywords: gravity, flotation, copper-molybdenum ore, tailings, centrifugal concentrators.

Citation: Algebraistova N.K., Markova A.S., Prokopiev I.V., Kolotushkin D.M. Possible methods recovery of metals from flotation tailings copper-molybdenum ores, J. Sib. Fed. Univ. Eng. technol., 2016, 9(5), 724-730. DOI: 10.17516/1999-494X2016-9-5-724-730.

(C) Siberian Federal University. All rights reserved

* Corresponding author E-mail address: markova-anya@mail.ru 


\title{
Возможные способы доизвлечения металлов \\ из хвостов флотации медно-молибденовых руд
}

\author{
Н.К. Алгебраистова, А.С. Маркова, \\ И.В. Прокопьев, Д.М. Колотушкин \\ Сибирский федеральный университет \\ Россия, 660041, Красноярск, пр. Свободный, 79
}

\begin{abstract}
Для снижения потерь металлов с хвостами коллективного циилла флотации медномолибденовой руды Сорского месторождения была выполнена предварительная оченка эффективности обогащения хвостов с использованием гравитационного и флотационного методов. Результаты исследований показали перспективность применения обоих методов, однако в случае гравитационного обогащения возможно извлечь ценный компонент без добавления флотационных реагентов, что благоприятно сказывается на процессе селекции коллективного концентрата, а также на окружающей среде.
\end{abstract}

Ключевые слова: гравитация, флотация, медно-молибденовые руды, хвосты, цчентробежные кониентраторы.

\section{Введение}

Как известно, медно-молибденовые руды обогащают по схемам коллективной флотации с последующим разделением коллективного концентрата на медный и молибденовый [1]. Применение таких схем в практике обогащения медно-молибденовых руд довольно распространено, так как это позволяет уже «в голове» схемы, при грубом измельчении руды (45-55 \% класса -0,071 мм), сбросить большую часть хвостов в отвал, что влечёт за собой значительное снижение затрат на измельчение, эксплуатационных затрат, а также сокращение фронта флотации.

Однако вследствие ухудшения качества руды: снижения содержания металлов, изменения фазового состава ценных компонентов, размера и характера вкрапленности, - имеют место потери металла с отвальными хвостами. Так, например, с хвостами Сорской обогатительной фабрики теряется $\sim 39$ \% меди и $\sim 15 \%$ молибдена. Поэтому вопрос сокращения потерь металлов с хвостами флотации актуален.

Доизвлечение ценных компонентов необходимо производить таким образом, чтобы не потребовалась существенная реконструкция технологического режима основного производства, а схемы доизвлечения должны быть простыми в применении.

\section{Экспериментальная часть}

Перед началом исследований с целью определения метода обогащения для извлечения сульфидной составляющей из хвостов был изучен гранулометрический состав отвальных хвостов Сорской фабрики. Результаты анализа показали, что в классе $+0,071$ содержится около половины медных минералов, в то время как большая часть молибдена сконцентрирована в классе крупности -0,071+0 мм (табл. 1).

Для доизвлечения ценных компонентов было решено изучить флотационный и гравитационный методы.

$$
-725-
$$


Natalia K. Algebraistova, Anna S. Markova... Possible Methods Recovery of Metals from Flotation Tailings...

Таблица 1. Распределение металлов по классам крупности в хвостах коллективного цикла флотации

\begin{tabular}{|c|c|c|c|c|c|}
\hline \multirow{2}{*}{$\begin{array}{c}\text { Классы } \\
\text { крупности, мм }\end{array}$} & \multirow{2}{*}{ Выход, \% } & \multicolumn{2}{|c|}{ Содержание, \% } & \multicolumn{2}{c|}{ Распределение металла, \% } \\
\cline { 3 - 6 } & & $\mathrm{Cu}$ & $\mathrm{Mo}$ & $\mathrm{Cu}$ & Мо \\
\hline$+0,071$ & 47,3 & 0,015 & 0,0058 & 50,79 & 22,73 \\
\hline$-0,071+0,04$ & 27,2 & 0,010 & 0,0050 & 19,41 & 11,14 \\
\hline$-0,04+0,02$ & 9,8 & 0,006 & 0,0053 & 4,43 & 4,30 \\
\hline$-0,02+0$ & 15,7 & 0,023 & 0,0473 & 25,38 & 61,83 \\
\hline Исходный & 100,0 & 0,014 & 0,0120 & 100,0 & 100,0 \\
\hline
\end{tabular}

Современное гравитационное оборудование способно извлекать в тяжёлую фракцию частицы крупностью до нескольких микрон [2]. Так, центробежные сепараторы широко используются при доизвлечении мелкого золота $[3,4]$.

Нами выполнены исследования на центробежных концентраторах Falcon L-40 и Итомак КН-0,1, а также винтовом шлюзе ВШ-350.

Условия реализации опытов были приняты из практики обогащения золотосодержащих руд $[5,6]$.

\section{Результаты исследования и их обсуждение}

Исследования показали, что молибденит не концентрируется в тяжёлой фракции (содержание ниже предела обнаружения), извлечение меди составило 7-9 \% при незначительной степени концентрации (табл. 2).

Чтобы повысить технологические показатели, выполнили опыты при тех же условиях, однако исходное питание довели до крупности 85 \% класса - 0,071 мм (табл. 3).

При обогащении посредством экологически безопасного, гравитационного, метода в тяжёлую фракцию удалось извлечь $20 \%$ меди, что сокращает потери металла с отвальными хвостами на $\sim 8 \%$.

Полученные результаты следует рассматривать как минимально возможные, оптимизация параметров процесса позволит более полно концентрировать металлы в тяжёлую фракцию. Так, молибден распределён на 61 \% в классе - 0,020 мм, а принятый расход воды для флюидизации соответствовал условиям обогащения золотосодержащих руд, т.е. природно-гидрофобный молибденит «уплыл» в лёгкую фракцию.

Флотационные исследования по извлечению сульфидов меди и молибденита из хвостов коллективного цикла осуществляли по схеме и режиму, представленному на рис. 1.

Эксперименты осуществлялись как на исходном питании (45 \% класса -0,071 мм) (рис. 1a), так и после его доизмельчения до 85 \% класса -0,071 мм (рис. 16). Полученные результаты приведены в табл. 4.

Как видно, флотационный метод позволяет в пенный продукт извлечь $24 \%$ меди и $~ 16 \%$ молибдена. Степень концентрации металлов при использовании флотационного метода выше в сравнении с гравитационным методом, выход пенного продукта составил $\sim 1 \%$.

Согласно технологической схеме гравиоконцентрат, полученный в процессе обогащения хвостов коллективного цикла, объединяется с коллективным концентратом флотации и на- 
Таблица 2. Результаты исследований гравитационным методом

\begin{tabular}{|c|c|c|c|c|c|}
\hline \multirow{2}{*}{ Продукт } & \multirow{2}{*}{ Выход, \% } & \multicolumn{2}{|c|}{ Содержание, \% } & \multicolumn{2}{|c|}{ Извлечение, \% } \\
\hline & & $\mathrm{Cu}$ & Mo & $\mathrm{Cu}$ & Mo \\
\hline \multicolumn{6}{|c|}{ Falcon L-40 } \\
\hline Тяжёлая фракция & 3,0 & 0,041 & $\mathrm{H} / \mathrm{O}$ & 8,7 & $\mathrm{H} / \mathrm{O}$ \\
\hline Лёгкая фракция & 97,0 & 0,014 & 0,012 & 91,3 & 100,0 \\
\hline Исходный & 100,0 & 0,014 & 0,012 & 100,0 & 100,0 \\
\hline \multicolumn{6}{|c|}{ Итомак КН-0,1 } \\
\hline Тяжёлая фракция & 4,2 & 0,024 & $\mathrm{H} / \mathrm{O}$ & 7,2 & $\mathrm{H} / \mathrm{O}$ \\
\hline Лёгкая фракция & 95,8 & 0,014 & 0,012 & 93,8 & 100,0 \\
\hline Исходный & 100,0 & 0,014 & 0,012 & 100,0 & 100,0 \\
\hline \multicolumn{6}{|c|}{ Винтовой шлюз ВШ-350 } \\
\hline Тяжёлая фракция & 5,7 & 0,017 & $\mathrm{H} / \mathrm{O}$ & 7,1 & $\mathrm{H} / \mathrm{O}$ \\
\hline Лёгкая фракция & 94,3 & 0,014 & 0,012 & 92,9 & 100,0 \\
\hline Исходный & 100,0 & 0,014 & 0,012 & 100,0 & 100,0 \\
\hline
\end{tabular}

Примечание: н/о - не обнаружено.

Таблица 3. Результаты опытов по гравитации после доизмельчения

\begin{tabular}{|c|c|c|c|c|c|}
\hline \multirow{2}{*}{ Продукт } & \multirow{2}{*}{ Выход, \% } & \multicolumn{2}{|c|}{ Содержание, \% } & \multicolumn{2}{|c|}{ Извлечение, \% } \\
\hline & & $\mathrm{Cu}$ & Mo & $\mathrm{Cu}$ & Mo \\
\hline \multicolumn{6}{|c|}{ Falcon L-40 } \\
\hline Тяжёлая фракция & 2,7 & 0,026 & $\mathrm{H} / \mathrm{O}$ & 5,1 & $\mathrm{H} / \mathrm{o}$ \\
\hline Лёгкая фракция & 97,3 & 0,014 & 0,012 & 94,9 & 100,0 \\
\hline Исходный & 100,0 & 0,014 & 0,012 & 100,0 & 100,0 \\
\hline \multicolumn{6}{|c|}{ Винтовой шлюз ВШ-350 } \\
\hline Тяжёлая фракция & 5,89 & 0,048 & $\mathrm{H} / \mathrm{O}$ & 20,2 & $\mathrm{H} / \mathrm{O}$ \\
\hline Лёгкая фракция & 94,11 & 0,012 & 0,012 & 79,8 & 100,0 \\
\hline Исходный & 100,0 & 0,014 & 0,012 & 100,0 & 100,0 \\
\hline
\end{tabular}

Примечание: н/о - не обнаружено.

правляется в цикл селекции. В данном случае применение гравитационного метода для доизвлечения металлов из хвостов флотации медно-молибденовых руд предпочтительнее, так как ранее проведённые исследования [7, 8] показали, что добавление гравиоконцентрата в процесс селекции благоприятно сказывается на последующем разделении. Это обусловлено тем, что при объединении флотационного и гравитационного концентратов происходит перераспределение остаточных концентраций ПАВ с поверхности флотационного концентрата на поверхность сульфидов тяжёлой фракции. Использование такой технологии позволит сократить расходы вредных реагентов в процессе селекции и в целом облегчит разделение коллективного концентрата. 


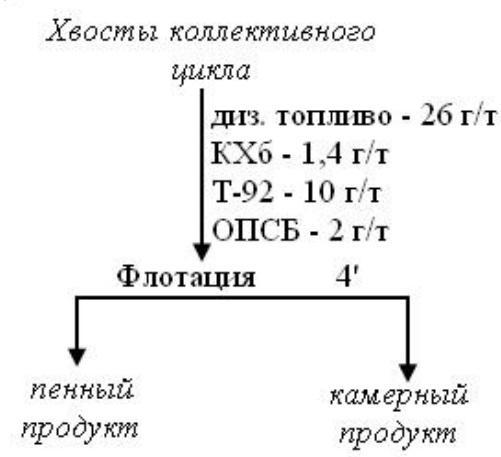

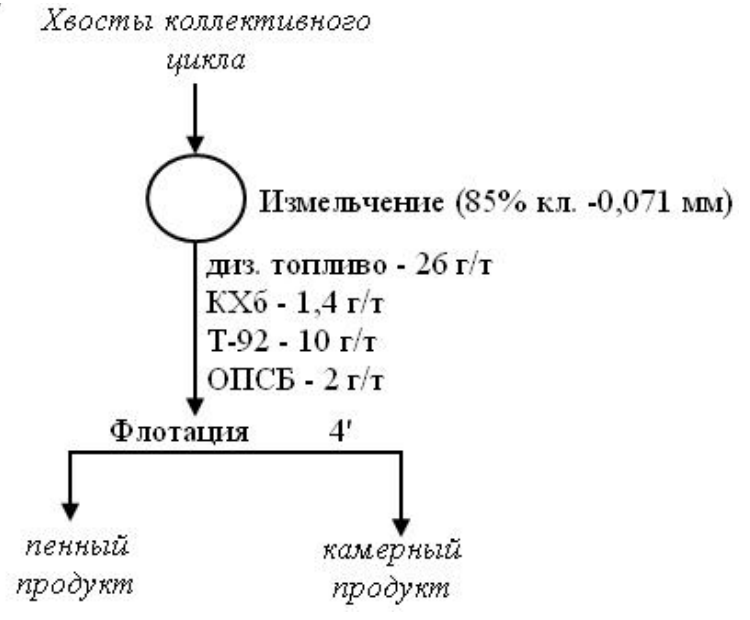

6

Рис. 1. Схемы выполнения флотационных опытов: а - крупность питания 45 \% класса -0,071 мм; б крупность питания 85 \% класса $-0,071$ мм

Таблица 4. Результаты опытов по флотации

\begin{tabular}{|l|c|c|c|c|c|}
\hline \multirow{2}{*}{ Продукт } & \multirow{2}{*}{ Выход, \% } & \multicolumn{2}{c|}{ Содержание, \% } & \multicolumn{3}{c|}{ Извлечение, \% } \\
\cline { 3 - 6 } & & $\mathrm{Cu}$ & $\mathrm{Cu}$ & \multicolumn{2}{c|}{$\mathrm{Cu}$} \\
\hline \multicolumn{7}{|c|}{ Питание, крупностью 45 \% класса -0,071 мм } \\
\hline Пенный продукт & 0,8 & 0,094 & 0,091 & 5,1 & 5,7 \\
\hline Камерный продукт & 99,2 & 0,014 & 0,012 & 94,9 & 94,3 \\
\hline Исходный & 100,0 & 0,015 & 0,013 & 100,0 & 100,0 \\
\hline \multicolumn{7}{|c|}{ Питание, крупностью $85 \%$ класса -0,071 мм } \\
\hline Пенный продукт & 0,9 & 0,376 & 0,219 & 24,1 & 16,4 \\
\hline Камерный продукт & 99,1 & 0,011 & 0,010 & 75,9 & 83,6 \\
\hline Исходный & 100,0 & 0,014 & 0,012 & 100,0 & 100,0 \\
\hline
\end{tabular}

\section{Выводы}

Исследованы хвосты коллективного цикла флотации медно-молибденовой руды для сокращения потерь ценных компонентов. Проведён анализ потерь металлов с хвостами коллективной флотации, который показал, что в классе $+0,071$ мм содержится около половины медных минералов, в то время как большая часть молибдена сконцентрирована в классе крупности $-0,071+0$ мм. На основании полученных результатов изучены наиболее универсальные методы обогащения - гравитационный и флотационный.

Показано, что извлечения меди в концентратные продукты двумя методами близки: в обоих случаях этот показатель $20 \%$. Применение флотационного метода позволяет доизвлечь $\sim 16$ \% молибдена. Полученные результаты являются минимально возможными, дальнейшая оптимизация параметров позволит повысить технологические показатели обогащения изученных процессов. 
Применение гравитационного метода для доизвлечения ценных компонентов из хвостов коллективного цикла флотации медно-молибденовых руд наиболее перспективно. Это обусловлено тем, что рекомендуемый метод экологичный, используемые аппараты характеризуются надежностью, а также не требуется существенной реконструкции технологического режима основного производства.

Исследование выполнено при финансовой поддержке РФФИ, грант № 15-45-04094 «Комбинированные исследования физико-химических, микробиологических и химических воздействий на твёрдые полезные ископаемые для повышения технико-экономических показателей обогащения»

\section{Список литературы}

[1] Алгебраистова Н.К., Макшанин А.В., Бурдакова Е.А., Самородский П.Н., Маркова А.С. Разработка стадиальной гравитационной схемы извлечения благородных металлов. Обогащение руд, 2015 (2), 3-7 [Algebraistova N.K., Makshanin A.V., Burdakova E.A., Samorodskiy P.N., Markova A.S. Development of stage gravity scheme for recovery of precious metals. Mineral processing, 2015 (2), 3-7 (in Russian)]

[2] Литвинцев В.С. Состояние и развитие технологий и горного оборудования для освоения россыпных месторождений благородных металлов. Горный информационно-аналитический бюллетень, 2009 4(12), 359-366 [Litvincev V.S. Status and development of technology and equipment for mining development of placer deposits of precious metals. Mining informational and analytical bulletin, 2009 4(12), 359-366 (in Russian)]

[3] Александрова Т.Н., Литвинова Н.М., Богомяков Р.В. К вопросу извлечения мелкодисперсного золота из песков россыпных месторождений. Горный информационно-аналитический бюллетень, 2011 (2), 319-323 [Aleksandrova T.N., Litvinova N.M., Bogomjakov R.V. To an extraction question melkodispersnogo gold from sand rossypnyh deposits, Mining informational and analytical bulletin, 2011 (2), 319-323 (in Russian)]

[4] Орлов Ю.А., Афанасенко С.И., Лазариди А.Н. Рациональное использование центробежных концентраторов при обогащении золоторудного сырья. Горный журнал, 1997 (11), 57-60 [Orlov Yu.A., Afanasenko S.I., Lazaridi A.N. Rational use of centrifugal concentrators in the beneficiation of gold ores. Mining jornal, 1997 (11), 57-60 (in Russian)]

[5] Алгебраистова Н.К., Гольсман Д.А.,. Ананенко К.Е, Гроо Е.А., Макшанин А.В. Гравитационные аппараты для предконцентрации металлов из убогих золото-кварцевых руд. Горныцй информационно-аналитический бюллетень, 2011 (3), 210-215 [Algebraistova N.K., Golsman D.A., Ananenko K.E., Groo E.A., Makshanin A.V. Gravity separators for preconcentration of metals from lowgrade gold-quartz ores. Mining informational and analytical bulletin, 2011 (3), 210-215 (in Russian)]

[6] Алгебраистова Н.К., Маркова А.С., Прокопьев И.В., Развязная А.В. Подготовка коллективных концентратов предприятий цветной металлургии к циклу селекции. Сборник докладов VII Международного конгресса «Цветные металль и минеральл», 2015, 136-138 [Algebraistova N.K., Markova A.S., Prokopiev I.V., Razvyaznaya A.V. Preparation collective concentrate non-ferrous enterprise to the selection. Proceedings of the VII International Congress «Non-Ferrous Metals and Minerals», 2015, 136-138 (in Russian)]

$$
-729-
$$


[7] Алгебраистова Н.К., Макшанин А.В., Маркова А.С. Изучение возможности выделения сульфидов меди и молибдена гравитацией. Сборник докладов международного совещания «Прогрессивные методы обогащения и комплексной переработки природного и техногенного минерального сырья (Плаксинские чтения-2014)», 2014, 221-222 [Algebraistova N.K., Makshanin A.V., Markova A.S. Study of a possibility separation of sulfides of copper and molybdenum by gravity method of enrichment. Proceedings of the international workshop «Advanced enrichment methods and complex processing of natural and technogenic mineral raw materials (Plaksin readings 2014)»2014, 221-222 (in Russian)] 